\title{
A Relação entre Universidade e Empresa Mediada pelos Núcleos de Inovação Tecnológica: Um Estudo na UTFPR
}

\section{The Relationship between University and Industry Mediated by Technological Innovation Centers: A Study at UTFPR}

\author{
Rafael Fernando Pequito Lima Mestrado em Propriedade Intelectual e Transferência de Tecnologia para Inovação. Universidade \\ Estadual de Maringá (UEM) - Brasil. rafaelpequito@gmail.com. \\ Rejane Sartori Doutorado em Engenharia e Gestão do Conhecimento. Universidade Estadual de Maringá (UEM). \\ Universidade Cesumar (Unicesumar) - Brasil. rejanestr@gmail.com
}

\section{RESUMO}

A inovação tem sido caracterizada como um processo interativo, em que o conhecimento é fundamental para as atividades inovativas. Nesse contexto, as universidades desempenham importante papel, pois atuam como agentes capazes de alavancar a inovação. Ao interagirem com empresas, são consideradas propulsoras de desenvolvimento econômico. Para gerir o processo de inovação, especialmente no âmbito das universidades, a Lei de Inovação instituiu a criação de um órgão denominado Núcleo de Inovação Tecnológica (NIT), responsável por promover um ambiente favorável ao relacionamento universidade-empresa. A Universidade Tecnológica Federal do Paraná (UTFPR), uma instituição multicampi, tem atuado de forma a aproximar-se do setor produtivo, e para tanto, conta com uma Agência de Inovação e 13 NITs, um em cada campi. Essa pluralidade de NITs, aliada à fragmentada regulamentação institucional sobre gestão da inovação, não tem favorecido o relacionamento da universidade com as empresas. Desse modo, o objetivo desta pesquisa é entender como ocorre a relação entre universidade-empresa na UTFPR, intermediado pelos seus NITs com vista a sugerir ações que favoreçam a aproximação desses atores. Esta é uma pesquisa de campo, com abordagem qualitativa e caráter exploratório. Os resultados, revelam que os NITs fornecem suporte aos pesquisadores e organizam atividades para promover a parceria com empresas, contudo, se deparam com diversas barreiras e dificuldades que impactam nesse processo. Assim, a UTFPR deve atuar de modo a incentivar e valorizar os pesquisadores a participarem de ações que favoreçam a relação universidadeempresa, consolidando a universidade como uma hélice atuante, tal qual prega a teoria da hélice tríplice.

Palavras-chaves: Relação universidade-empresa. Gestão da Inovação. Núcleos de Inovação Tecnológica.

\begin{abstract}
Innovation has been characterized as an interactive process, in which knowledge is essential for innovative activities. In this context, universities play an important role, as they act as agents capable of leveraging innovation. When interacting with companies, they are considered drivers of economic development. To manage the innovation process, especially within universities, the Innovation Law instituted the creation of a body called the Technological Innovation Center (NIT), responsible for promoting a favorable environment for the university-company relationship. The Federal Technological University of Paraná (UTFPR), a multicampi institution, has been working in order to get closer to the productive sector, and for that, it has an Innovation Agency and 13 NITs, one on each campuses. This plurality of NITs, combined with the fragmented institutional regulation on innovation management, has not favored the university's relationship with companies. Thus, the objective of this research is to understand how the relationship between university and company in UTFPR occurs, intermediated by its NITs in order to suggest actions that favor the approach of these actors. This is a field research, with a qualitative approach and exploratory character. The results, reveal that the NITs provide support to researchers and organize activities to promote partnership with companies, however, they face several barriers and difficulties that impact this process. Thus, UTFPR must act in a way to encourage and value researchers to participate in actions that favor the university-company relationship, consolidating the university as an active propeller, just as the theory of the triple helix preaches.
\end{abstract}

Keywords: Innovation. Innovation management. University-industry linkages. Technology transfer office. 


\section{INTRODUÇÃO}

A inovação está presente na agenda de diversos países, sendo apontada como sinônimo de progresso, desenvolvimento tecnológico, criação de empregos, melhoria nas condições de vida e bem-estar das pessoas (CADORI, 2013). É caracterizada como um processo interativo, em que o compartilhamento de conhecimento entre e dentro das firmas e em colaboração com outras entidades é de grande importância para as atividades inovativas (CASTRO; TEIXEIRA; LIMA, 2014).

A origem do conceito de inovação é atribuída aos estudos de Joseph Schumpeter (1883-1950), ao considerar que inovar diz respeito a produzir outras coisas, ou as mesmas coisas de maneira distinta, combinar de modo diferente materiais e forças, realizar novas combinações (SCHUMPETER, 1984). O Manual de Oslo, produzido pela Organização para a Cooperação e o Desenvolvimento Econômico (OCDE), define inovação como a "introdução de um bem ou serviço novo ou significativamente melhorado, no que se refere às suas características ou usos previstos, ou ainda, à implementação de métodos ou processos de produção, distribuição, marketing ou organizacionais novos ou significativamente melhorados" (OCDE, 2018). A inovação está relacionada ao conhecimento, uma vez que cria novas possibilidades por meio de combinações de diferentes tipos de conhecimento, que pode ser aquele já existente, que resulta da busca por tecnologia, das necessidades do mercado, e que pode ser compartilhado, acessado e transferido (TIDD; BESSANT; PAVIT, 2008).

Nesse contexto, a educação é percebida como alicerce fundamental para o processo de inovação (ALVES; SEGUNDO; SAMPAIO, 2015), sendo que as universidades têm contribuído para o desenvolvimento da capacidade de inovação em nosso país ao menos em dois aspectos principais: formação de alunos para inovação, com a incorporação pelas empresas dos graduados, aumentando assim a cultura da inovação e o empreendedorismo; e junção dos resultados das pesquisas e criações universitárias em benefício da sociedade (LOTUFO, 2009). A interação entre a produção científica e a produção tecnológica desempenha importante papel para a economia e para os sistemas nacionais de inovação em diversos países e representa o mesmo no Brasil (PUFFAL; COSTA, 2010).

Diversas nações buscaram criar mecanismos de aproximação entre o que é produzido na academia com as necessidades do mercado. No Brasil, a Lei de Inovação, promulgada em 2004, é considerada o primeiro normativo legal que estimula a relação entre universidade e empresa no país. Esta Lei estabeleceu medidas de incentivo à inovação e à pesquisa científica e tecnológica no ambiente produtivo, bem como determinou que as Instituições Científicas, Tecnológicas e de Inovação (ICTs) deveriam dispor de Núcleos de Inovação Tecnológica (NITs) para gerir sua política de inovação (BRASIL, 2004). Essa Lei foi revitalizada com a recente edição, em 2016, do Marco Legal da Ciência, Tecnologia e Inovação (CT\&l), que ampliou as competências atribuídas até então aos NITs, indicando serem estes os órgãos responsáveis por promover a proteção das invenções geradas nas ICTs, a transferência de tecnologia ao setor produtivo, bem como favorecer o relacionamento das ICTs com as empresas, contribuindo assim para o desenvolvimento cultural, tecnológico e social da região (BRASIL, 2016).

Os NITs desempenham papel fundamental na relação entre as ICTs e as empresas, adotando estratégias e diretrizes previstas nas políticas públicas de inovação para estimular a transferência das tecnologias desenvolvidas nas universidades para o setor produtivo. Foram criados justamente para promover um ambiente favorável a parcerias estratégicas entre as universidades, institutos tecnológicos e indústria (SILVA, 2013; PIRES; QUINTELLA, 2015). Assim, por meio dos NITs, as universidades desempenham importante função uma vez que atuam como agentes capazes de alavancar a inovação. Neste mesmo sentido, as universidades são vistas como importantes atores para a governança local e regional, pois seu capital humano pode contribuir com o desenvolvimento regional, e para isto, é importante a interação com os atores locais da sociedade civil (SEDLACEK, 2013).

A Universidade Tecnológica Federal do Paraná (UTFPR), ao longo de sua existência, tem atuado de forma a estabelecer um forte relacionamento com o setor produtivo. Está presente em 13 municípios do Estado do Paraná, e para gerir sua política de inovação e promover sua aproximação com o ambiente empresarial, conta com uma Agência de Inovação e NITs estruturados em cada um dos campi. Desse modo, possui 13 NITs para promover a interação entre a UTFPR e as empresas. 
A pluralidade de NITs dessa universidade, os quais foram instituídos em diferentes momentos e, consequentemente, se encontram em distintos estágios de desenvolvimento, assim como a fragmentada regulamentação institucional relativa à gestão da inovação, propriedade intelectual e transferência de tecnologia, não tem favorecido a compreensão da própria comunidade acadêmica e da sociedade sobre o processo de relação entre a UTFPR e as empresas. Desse modo, o objetivo desta pesquisa é entender como ocorre a relação entre universidade-empresa na UTFPR, intermediado pelos seus NITs, com vistas a sugerir ações que favoreçam a aproximação desses atores.

Esta pesquisa apresenta relevância agora em que as universidades buscam uma redefinição de seu papel na sociedade e as empresas novas alternativas para garantir sua permanência no mercado. Uma adequada participação dos NITs no processo de inovação, atuando com as partes envolvidas, pesquisadores e empresários, pode propiciar uma interação mais efetiva e gerar melhores resultados, contribuindo assim para uma economia mais consolidada que gere e distribua riqueza no país.

\section{A INOVAÇÃO E A RELAÇÃO UNIVERSIDADE-EMPRESA}

Nos dias atuais, há uma percepção generalizada de que o conhecimento se tornou essencial para a geração de riqueza e promoção do bem-estar social. O conhecimento estrutura a capacidade de inovação, uma vez que o processo de inovação utiliza conhecimento para criar ou melhorar produtos, processos ou serviços e inovar aqueles já existentes (SARTORI, 2017).

O processo de inovação é crescentemente caracterizado por atividades em redes de cooperação, envolvendo a participação interativa de múltiplos atores, tais como governos, empresas, universidades e usuários (MARUYAMA; RAPCHAN, 2016). Conscientes de que podem contribuir com esse processo por meio de suas atividades, as universidades se constituem em ambientes propícios à inovação, pois possuem capacidade, recursos e potencial que devem ser combinados para estimular o surgimento de espaços de inovação (FREITAS JUNIOR et al., 2013; STEFANO; SARTORI; LAUX, 2017).

A universidade brasileira, em especial a pública, experimentou nos últimos anos um período de expansão e transformações, porém, tem sido questionada sobre vários pontos, entre eles, a integração com o governo e o setor produtivo e a maneira como tem utilizado os recursos provenientes da sociedade (FREITAS JUNIOR et al., 2013). Como afirmam Etzkowitz e Zhou (2017, p. 23), "a universidade está deixando de ter um papel social secundário, ainda que importante, de prover ensino superior e pesquisa, e está assumindo um papel primordial equivalente ao da indústria e do governo, como geradora de novas indústrias e empresas". Assim sendo, a aproximação da universidade com o setor empresarial faz parte da agenda de todas as instituições e gera novos resultados e desafios, destacando-se o crescimento da participação acadêmica na proteção de propriedade intelectual e no licenciamento de tecnologias para o segmento empresarial e industrial (PIRES; QUINTELLA, 2015).

A Lei de Inovação, promulgada em 2004, determinou a criação dos NITs, os quais, conforme afirma Cabrera (2012), são ou devem ser estruturados para introduzir uma nova sinergia na gestão das relações das ICTs com o setor produtivo. Para Lotufo (2009), esse foi o primeiro instrumento jurídico legal do país voltado para incentivar o relacionamento entre universidade e empresa, traçando as primeiras diretrizes para viabilizálo.

O surgimento dos NITs é um dos resultados dos esforços do Brasil para se tornar um país competitivo e inovador, que se iniciou com a Conferência Nacional de CT\&l, realizada em 2001. Os NITs possuem papel fundamental para promover o conhecimento e o uso de novas tecnologias brasileiras oriundas das universidades para a sociedade, empresas ou indústrias (COSTA, 2013). O processo de inovação e a transferência de tecnologia, os fatores de estreitamento das relações entre universidade e empresa e a responsabilidade pelo aproveitamento das pesquisas científicas e tecnológicas pelo setor produtivo também são ações de competência dos NITs, e por meio desta gama de atividades é possível perceber sua importância para as universidades brasileiras (SILVA, 2013). Assim, cabe aos NITs gerenciar a inovação nas universidades e tornar mais eficaz a relação entre a universidade e o setor produtivo, as quais devem considerar variáveis 
externas e internas, tais como fatores ambientais, inserção na sociedade, marco legal, gestão organizacional, gestão de recursos humanos e estratégia de negócios (DIAS; PORTO, 2013).

Nesse contexto, Etzkowitz e Leydesdorff (2000) apresentaram o modelo da Tríplice Hélice, discutindo a relação universidade-empresa-governo e explicando a evolução estrutural das economias baseadas no conhecimento. Esse modelo considera a universidade como instituição central do conhecimento e promotora das relações entre o setor produtivo e o governo. À universidade cabe produzir novos conhecimentos, fomentar a inovação tecnológica e incorporar novas funções no desenvolvimento econômico.

A Hélice Tríplice, em uma dinâmica interativa, passou por um processo evolutivo até chegar ao modelo de inter-relação entre os três elementos. Assim, de acordo com Etzkowitz e Leydesdorff (2000), originalmente na Tríplice Hélice I privilegiava-se o Estado em relação à universidade e ao setor produtivo; na Hélice Tríplice II consideravam-se as esferas institucionais separadamente, com fronteiras de atuação bem delimitadas e baixa interação entre as instituições; e na Tríplice Hélice III as esferas institucionais ultrapassam suas funções, havendo sobreposição de atividades.

No entender desses autores, as inovações institucionais são as responsáveis pela aproximação das universidades e empresas, com apoio governamental. Na Tríplice Hélice o conhecimento está em constante fluxo entre esses três atores. Esse modelo não é visto como uma estrutura estável, mas sim de organizações híbridas, onde governo, universidade e empresa podem se relacionar com um mesmo grau de importância, podendo existir sobreposição de papeis quando necessário ao processo de inovação. Assim, a Hélice Tríplice é muito mais do que interação entre universidade, governo e setor produtivo; implica na transformação interna de cada uma dessas esferas, fruto de uma nova economia baseada no conhecimento. $O$ papel que a universidade desempenha nesse contexto tem criado o termo "universidades empreendedoras" devido ao seu fortalecimento, articulando o ato de empreender às atividades já desempenhadas de ensino e pesquisa.

Com as transformações no entendimento do processo de inovação, Toledo (2015) argumenta que os resultados das pesquisas universitárias começaram a ser vistos não só como avanços da fronteira do conhecimento, mas como uma rica fonte de novas ideias que podem gerar inovações. Por meio de suas competências científicas, a universidade influencia o processo de inovação, seja por sua participação em projetos colaborativos com empresas ou prestação de serviços tecnológicos.

Cada vez mais, inclusive nas economias em desenvolvimento, espera-se que as universidades se tornem mais ágeis e desempenhem um papel onde o conhecimento contribua para o desenvolvimento econômico e social (LEMOS; CARIO, 2015). As empresas possuem conhecimento das demandas de mercado, disponibilidade de recursos para investimentos em inovação e capacidade para implementar novas ideias. A universidade, por sua vez, detém o conhecimento científico, pesquisadores e estruturas, que podem contribuir de forma significativa para a evolução das técnicas aplicadas no setor produtivo (BERNI et al., 2015).

Diversos autores relatam as distintas maneiras pelas quais a cooperação entre universidade e empresa pode ocorrer. Toledo (2015) menciona desde formas mais sutis, como o oferecimento de estágios profissionalizantes, até as mais complexas e abrangentes, como nos grandes programas de pesquisa cooperativa.

Alguns dos canais de interação entre universidade e empresa descritos por Rosa (2015) são: publicações e apresentações em congresso; patenteamento dos resultados de pesquisa; licenças (i.e., direitos legais para utilizar a propriedade intelectual gerada na universidade); spin-off acadêmica (formação de empresa por meio de pesquisa universitária ou licenciada pela universidade), financiamento de pesquisa; contatos informais entre pesquisador e diretor de pesquisa da empresa; e compartilhamento de pessoal (i.e., pesquisadores trabalham temporariamente em empresa).

Para Algieri, Aquino e Sucurro (2013) e Pires (2014), a transferência de conhecimento e de tecnologia, de maneira mais informal ou simples, pode ser realizada por meio de publicações, de formação de alunos e de realização de conferências e workshops. Mais recentemente passou-se a estimular que a transferência de tecnologia ocorra por meio da propriedade intelectual, licenciamento de patentes, criação de empresas por meio de incubadoras ou parques tecnológicos, permitindo assim uma nova dimensão de oportunidades de pesquisa para professores e estudantes. 
Vários pontos relacionados ao processo de cooperação entre universidade e empresa são considerados como facilitadores e outros tantos como barreiras. Autores como Link, Siegel e Bozeman (2006), Carvalho e Cunha (2013) e Pires (2014) consideram como facilitadores para a relação universidade-empresa e para o processo de transferência de tecnologia: (a) a existência dos NITs; (b) a disponibilidade e possibilidade de recursos em projetos que contemplam a parceria universidade-empresa; (c) as possibilidades de interação criadas pela Lei de Inovação, pelo Marco Legal de CT\&I e pela Lei do Bem; (d) o fortalecimento de uma cultura voltada à interação e à transferência de tecnologia por parte das empresas; (e) as adequações jurídicas das universidades para apoiar os pesquisadores no relacionamento com as empresas; e (f) os centros de inovação, pesquisa cooperativa, parques tecnológicos e incubadoras de empresas.

Em estudos sobre a relação universidade-empresa, diversos fatores motivadores para essa cooperação foram identificados, os quais se encontram relacionados no Quadro 1.

Quadro 1 - Fatores motivadores para a relação universidade-empresa

\begin{tabular}{|c|c|}
\hline Universidade & Empresa \\
\hline $\begin{array}{l}\text { - Ausência de fontes financiadoras públicas para } \\
\text { pesquisa. } \\
\text { - Carência de recursos institucionais para } \\
\text { desenvolvimento de pesquisas. } \\
\text { - Obtenção de recursos financeiros e materiais } \\
\text { adicionais. } \\
\text { - Realização da função social. } \\
\text { - Aumento do prestígio institucional com a } \\
\text { divulgação da boa imagem da universidade. }\end{array}$ & $\begin{array}{l}\text { - Carências de recursos. } \\
\text { - Custos do licenciamento de tecnologia } \\
\text { estrangeira. } \\
\text { - Boas experiências em cooperações anteriores. } \\
\text { - Acesso às fronteiras científicas do } \\
\text { conhecimento e recursos humanos altamente } \\
\text { qualificados da universidade. } \\
\text { - Estímulo à criatividade e compartilhamento e } \\
\text { redução dos riscos da inovação. }\end{array}$ \\
\hline
\end{tabular}

Fonte: Elaborado pelos autores a partir de Bonnacorsi e Piccaluga (1994), Segatto-Mendes e Sbragia (2002), Fabiano (2012) e Silva (2015).

Já quanto à existência de barreiras na relação universidade-empresa, diversos autores mencionam que estas afetam tanto as empresas como os pesquisadores e os NITs. Assim, seguindo essa categorização, no Quadro 2 estão sistematizadas as principais barreiras identificadas na literatura. 
Quadro 2 - Barreiras da relação universidade-empresa

\begin{tabular}{|c|c|c|}
\hline Para Empresa & Para Pesquisador & Para NIT \\
\hline $\begin{array}{l}\text { - Burocracia universitária. } \\
\text { - Duração muito longa dos } \\
\text { projetos. } \\
\text { - Diferença de nível de } \\
\text { conhecimento entre as } \\
\text { pessoas da universidade e } \\
\text { das empresas envolvidas na } \\
\text { cooperação. } \\
\text { - Falta de conscientização da } \\
\text { comunidade acadêmica } \\
\text { sobre a importância da } \\
\text { parceria com o setor } \\
\text { produtivo. } \\
\text { - Necessidade de mudança } \\
\text { de cultura da universidade e } \\
\text { do setor produtivo sobre as } \\
\text { questões de propriedade } \\
\text { intelectual e inovação. }\end{array}$ & 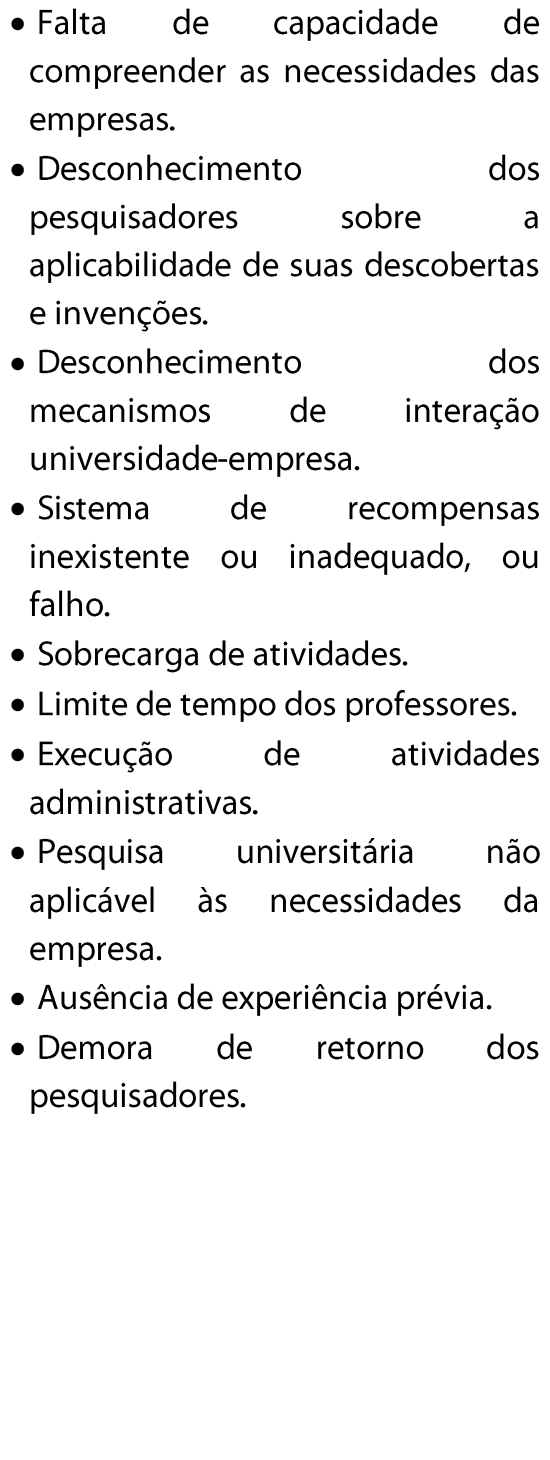 & 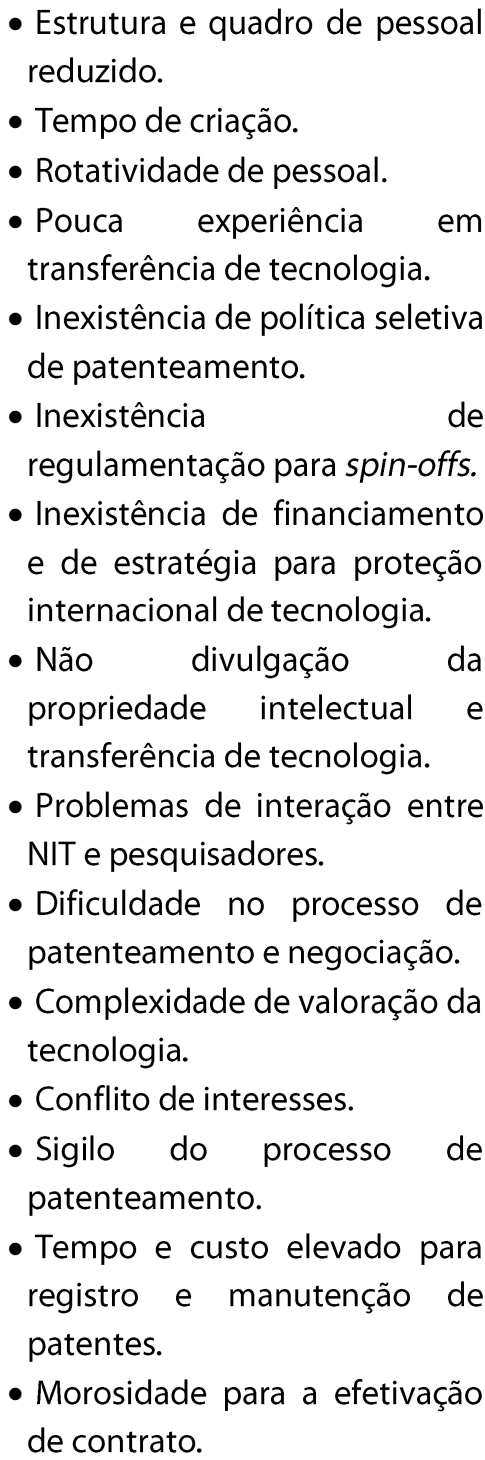 \\
\hline
\end{tabular}

Fonte: Elaborado pelos autores a partir de Segatto-Mendes e Sbragia (2002), Garnica e Torkomian (2009), Santana e Porto (2009), D'Este e Perkmann (2011), Kaymaz e Yasin Eryigit(2011), Fabiano (2012), Ferreira, Soria e Closs (2012), Noveli e Segatto (2012), Dias e Porto (2013), Silva, Kovaleski e Gaia (2013), Ferreira, Amaral e Leopoldi (2013), Desidério e Zilber (2014), Dias e Porto (2014), Rosa (2015) e Silva (2015).

Apesar das diversas barreiras e dificuldades, a relação universidade-empresa torna-se cada vez mais relevante, uma vez que as universidades, por meio de suas pesquisas, expandiram seus papeis em muitos campos. Mais do que um local para educação, conhecimento e formação de talentos de alta qualidade, na era da economia baseada no conhecimento essas instituições trazem grandes contribuições para os progressos tecnológicos e econômicos, com crescimento por meio da transferência de tecnologia, do fortalecimento da relação universidade-empresa e até mesmo da criação de spin-offs (SU et al., 2015).

\section{METODOLOGIA}

Esta pesquisa possui abordagem qualitativa, de caráter exploratório e de natureza aplicada. Inicialmente, efetuou-se uma pesquisa bibliográfica visando reconhecer elementos sobre o tema relação universidade-empresa. Para tanto, foram consultadas a base de dados Scopus e o Catálogo de Teses e 
Dissertações da Coordenação de Aperfeiçoamento de Pessoal de Nível Superior (Capes). Justifica-se a escolha da Scopus por sua representatividade internacional, considerada a maior base de referências bibliográficas de literatura, revisada por pares, permitindo uma visão multidisciplinar e integrada de fontes relevantes para o trabalho (CAPES, 2013), e o Catálogo da Capes por disponibilizar teses e dissertações defendidas no país desde 2013.

Os critérios estabelecidos para a pesquisa foram recorte temporal a partir de 2013 e utilização das seguintes palavras-chave: relação universidade-empresa, transferência de tecnologia e núcleo de inovação tecnológica para a pesquisa no Catálogo da Capes, e as equivalentes em inglês, university-industry linkages, tecnology transfer e tecnology transfer office para a Scopus. A pesquisa foi realizada em outubro de 2017 e resultou em um total de 62 trabalhos científicos (38 na Capes e 24 na Scopus). O processo de análise desses documentos envolveu a leitura de títulos e resumos, sendo então selecionados 27 para leitura completa, dos quais nove (dois da Scopus e sete da Capes) foram utilizados para compor o quadro teórico desta pesquisa.

Na sequência, foi efetuada uma pesquisa de campo com o propósito de conhecer a percepção dos gestores de inovação da UTFPR quanto ao processo de interação universidade-empresa. A pesquisa de campo procura o aprofundamento de uma realidade específica e é basicamente realizada por meio da observação direta das atividades do grupo estudado e de entrevistas com informantes para captar as explicações e interpretações do que ocorre naquela realidade (GIL, 2008).

Assim, a coleta de dados foi efetuada por meio de entrevistas realizadas com esses gestores, e para tanto, foi utilizado como instrumento um roteiro semiestruturado, composto por 13 questões abertas, elaboradas a partir da revisão bibliográfica, apresentado no Quadro 3.

\section{Quadro 3 - Roteiro da entrevista}

\begin{tabular}{|c|l|}
\hline N. & \multicolumn{1}{|c|}{ Pergunta } \\
\hline 1 & $\begin{array}{l}\text { Quais mecanismos são empregados pela UTFPR para promover a interação entre a Instituição e as } \\
\text { empresas? }\end{array}$ \\
\hline 2 & Qual o papel do NIT nesse processo? \\
\hline 3 & Quais ações do NIT contribuem para a efetivação da cooperação entre a UTFPR e as empresas? \\
\hline 4 & A UTFPR tem dificuldades para efetivar a relação universidade-empresa? Quais as principais? \\
\hline 5 & Quais ações poderiam ser propostas pelo NIT para minimizar essas dificuldades? \\
\hline 6 & $\begin{array}{l}\text { Quais os principais entraves burocráticos com os quais a UTFPR se depara para promover a relação } \\
\text { entre a universidade e a empresa? E o NIT, encontra entraves burocráticos? }\end{array}$ \\
\hline 7 & Quais ações poderiam ser propostas pelo NIT para minimizar esses entraves burocráticos? \\
\hline 8 & $\begin{array}{l}\text { Quais são as barreiras/dificuldades relacionadas ao pesquisador que dificultam a efetivação da } \\
\text { relação universidade-empresa no âmbito da UTFPR? }\end{array}$ \\
\hline 9 & Quais os principais fatores que desestimulam os pesquisadores a realizar pesquisas com empresas? \\
\hline 10 & Quais ações poderiam ser propostas pelo NIT para minimizar esses fatores? \\
\hline 11 & $\begin{array}{l}\text { Quais são as barreiras/dificuldades relacionadas às empresas que podem dificultar a efetivação da } \\
\text { relação universidade-empresa no âmbito da UTFPR? }\end{array}$ \\
\hline 12 & Quais ações poderiam ser propostas pelo NIT para minimizar essas barreiras/dificuldades? \\
\hline 13 & Gostaria de acrescentar algum assunto que considera relevante e não foi perguntado? \\
\hline
\end{tabular}

Fonte: Elaborado pelos autores (2020).

Inicialmente, uma mensagem eletrônica foi enviada a 14 gestores de inovação da UTFPR, isto é, um gestor de cada um dos NITs dos 13 campi da Instituição e um da Agência de Inovação, informando o objetivo da pesquisa e convidando-os para participar da entrevista, contudo, obteve-se retorno de somente cinco gestores. Diante disso, foi efetuado contato telefônico com aqueles que ainda não haviam respondido a mensagem (nove) a fim de reiterar o convite e proceder ao agendamento da entrevista. Ao final de todas as comunicações, dez gestores concordaram em participar da pesquisa. No Quadro 4 é possível verificar o perfil de cada entrevistado, os quais foram mantidos em anonimato para preservar os pontos de vista dos 
participantes e para tanto, serão referidos ao longo do trabalho seguindo conotação alfabética, ou seja, "Entrevistado A, B, C, D, E, F, G, H, I, e J".

Quadro 4-Perfil dos entrevistados

\begin{tabular}{|c|c|c|c|}
\hline Entrevistado & Formação & Titulação & $\begin{array}{c}\text { Tempo de atuação } \\
\text { como gestor de } \\
\text { inovação na UTFPR }\end{array}$ \\
\hline A & Engenharia Industrial Elétrica & Doutorado & 5 anos \\
\hline B & Direito & Especialista & 6 anos \\
\hline C & Engenharia Elétrica & Mestrado & 25 meses \\
\hline D & Ciências Contábeis & Especialista & 3 anos e 8 meses \\
\hline E & Direito & Graduado & 9 anos \\
\hline F & Tecnologia em Alimentos & Especialista & 8 anos \\
\hline G & Tecnologia em Automação Industrial & Doutorado & 8 meses \\
\hline H & Licenciatura em Ciências & Doutorado & 5 anos \\
\hline I & Administração & Doutorado & 10 meses \\
\hline J & Agronomia & Doutorado & 2 anos \\
\hline
\end{tabular}

Fonte: Elaborado pelos autores (2020).

As entrevistas foram realizadas entre os meses de abril e maio de 2018. Nesta fase também foram considerados os procedimentos éticos: aos entrevistados foram explicados os objetivos da pesquisa e entregue um termo de consentimento livre e esclarecido. Ao concordar com a pesquisa, o entrevistado assinava o documento e dava-se sequência à entrevista. Duas entrevistas foram realizadas presencialmente e três por meio de comunicação eletrônica utilizando-se o software Skype, sendo que cinco entrevistados solicitaram que as respostas fossem enviadas de forma escrita, por mensagem eletrônica.

Após a realização das entrevistas, foi efetuada a transcrição dos áudios gravados e realizados registros com a utilização do aplicativo Microsoft Excel. Esses dados foram então analisados, de modo a conhecer a percepção dos gestores de inovação da UTFPR quanto ao processo de interação universidade-empresa. Para tanto, utilizou-se o método de análise de conteúdo de Bardin (2011), que compreende três etapas: a préanálise, que envolveu a organização do conteúdo das entrevistas transcritas; a exploração do material, que abarcou uma codificação para interpretação dos dados; e o tratamento dos resultados, que incluiu uma análise crítica a respeito das falas dos entrevistados.

\section{RESULTADOS E DISCUSSÕES: O PROCESSO DE INTERAÇÃO UNIVERSIDADE-EMPRESA NA UTFPR}

A UTFPR é a primeira universidade federal no Brasil a possuir em seu nome a palavra "tecnológica". Surgiu com a promulgação da Lei no 11.184, de 2005, mediante a transformação do então Centro Federal de Educação Tecnológica do Paraná (CEFET-PR) em universidade. Tem uma longa trajetória com a educação profissional e um bom relacionamento com a indústria, o que a leva a atuar fortemente com o segmento empresarial (UTFPR, 2017).

Instalada em 13 municípios do Estado do Paraná - Apucarana, Campo Mourão, Cornélio Procópio, Curitiba, Dois Vizinhos, Francisco Beltrão, Guarapuava, Londrina, Medianeira, Pato Branco, Ponta Grossa, Santa Helena e Toledo - a UTFPR tem como missão "desenvolver a educação tecnológica de excelência por meio do ensino, pesquisa e extensão, interagindo de forma ética, sustentável, produtiva e inovadora com a comunidade para o avanço do conhecimento e da sociedade". A UTFPR oferece mais de 100 cursos superiores e ainda cursos técnicos integrados para o nível médio. Possui mais de 40 programas de pós-graduação stricto sensu e oferece em torno de 90 cursos de pós-graduação lato sensu (UTFPR, 2017).

A Agência de Inovação da UTFPR foi oficialmente instituída em 2007 e atua por meio dos NITs criados em cada um dos 13 campi da instituição, com a finalidade de auxiliar a comunidade interna local em assuntos relacionados à inovação e propriedade intelectual. Ademais, vários são os instrumentos normativos internos 
que apoiam a gestão da inovação na UTFPR, tais como Regimento Geral, Regimento dos Campi, Regulamento do Conselho de Relações Empresariais e Comunitárias, Regulamento de Propriedade Intelectual e Regulamento do Comitê de Propriedade Intelectual, demonstrando assim o comprometimento da instituição com a inovação e sua aproximação com o setor produtivo (UTFPR, 2017).

As diversas ações realizadas pela UTFPR que impactam na sua relação com as empresas e que pertencem ao escopo de atuação dos NITs são: Apoio tecnológico, bolsas para servidores e alunos, editais de fomento, eventos de empreendedorismo e inovação, fórum de relações empresariais e comunitárias, pesquisa cooperativa, hotel tecnológico, incubadora de inovações, projetos tecnológicos e trabalho esporádico e trabalho regulamentado.

Entrevistas realizadas com os dez gestores de inovação da UTFPR revelaram que seis são docentes e quatro técnicos administrativos; cinco possuem dedicação de 40 horas semanais e outros cinco não têm essa dedicação integral, acumulando a atividade de gestor de inovação com as de docência e outras administrativas. Ademais, nenhum dos entrevistados exerce a função de gestor de inovação a mais de 10 anos, sendo que quatro atuam há aproximadamente dois anos, cinco há mais de cinco anos e apenas um está entre dois e cinco anos no cargo. Como apontado por diversos autores (Quadro 2), reduzido quadro de funcionários, rotatividade de pessoal e pouca experiência em transferência de tecnologia são fatores relacionados ao capital humano e se constituem em barreiras para a relação universidade-empresa. É possível afirmar, a partir das respostas dos entrevistados, que o tempo no cargo/função influenciou na percepção ou qualidade das respostas ao questionário proposto.

Quando questionados sobre os mecanismos empregados pela UTFPR para promover a interação entre a universidade e as empresas, seis respondentes mencionaram a realização de eventos para empresários, organizados justamente para aproximar a UTFPR das empresas. Foram citados ainda estágios, visitas técnicas em empresas, participação em organizações e em programas de desenvolvimento regional. Isto corrobora com as afirmações de Algieri, Aquino e Scurro (2013) e Pires (2014), de que o relacionamento universidadeempresa, bem como a transferência de conhecimento, pode ocorrer de maneira informal, tais como conferências e workshops, e como ressalta Toledo (2015), de formas sutis, como o estágio profissionalizante, ou ainda complexas e abrangentes, como programas de pesquisa cooperativa.

Em relação ao papel dos NITs no processo de interação da UTFPR com as empresas, oito respondentes afirmaram que esses órgãos atuam como suporte aos pesquisadores, apoiando a formalização da relação universidade-empresa, e fomentam e organizam atividades para a UTFPR se relacionar com as empresas, conforme relatado pelo Entrevistado D:

O NIT busca auxiliar o servidor e a empresa no que tange à elaboração de projetos, convênios de parceria, orientações relacionadas à propriedade intelectual, hotel tecnológico, entre outros. O NIT também faz a ponte de contato, quando necessário, entre empresa e universidade, e se encarrega dos trâmites administrativos.

Isso vem ao encontro do apontado por Link, Siegel e Bozeman (2006), Carvalho e Cunha (2013) e Pires (2014), que consideram como facilitadores para a relação universidade-empresa a existência de NITs. Ademais, como afirmam Costa (2013), os NITs possuem papel fundamental para promover o conhecimento e o uso de novas tecnologias oriundas das universidades.

Entre as ações realizadas pelos NITs que contribuem para a efetivação da cooperação entre a UTFPR e as empresas, quatro respondentes destacaram o apoio para a elaboração de parcerias e formalização de contratos, bem como a forma na qual o servidor pode efetivar a relação entre a universidade e as empresas. Também foi dito que os NITs atuam para intensificar os mecanismos já propostos e identificar demandas. Nesse sentido, o Entrevistado F afirmou que:

O Núcleo de Inovação propõe ações que intensificam os mecanismos já propostos pela UTFPR mas de uma maneira mais intensa e regional, sempre respeitando as diferenças entre as características de cada região. As ações são mais incisivas, o contato é mais próximo do agente inovador, possibilitando uma maior aproximação de ambos, aumentando esta sinergia. 
Por sua vez o Entrevistado G mencionou que cabe ao NIT "esclarecer para os pesquisadores os caminhos legais. Os servidores têm receio do que pode e não pode fazer; divulgar os ganhos; como os servidores podem realizar a interação, sendo esse o grande papel do NIT". Tais respostas corroboram com o apontado por Maruyama e Rapchan (2016), de que o processo de inovação é cada vez mais caracterizado por atividades em redes de cooperação, envolvendo a participação interativa de múltiplos atores, tais como governo, empresas, universidades e usuários.

Em relação às dificuldades encontradas pela UTFPR para efetivar a cooperação entre universidade e empresa, nove entrevistados responderam positivamente, enfatizando que estas se dividem em burocracia do setor público, combinado com o tempo da empresa ser diferente da universidade e a formação pretérita do docente não ser pensada para realizar a interação universidade-empresa, sendo esta mais voltada à pesquisa básica ou pura. $\mathrm{O}$ Entrevistado $\mathrm{C}$ afirmou que uma das grandes dificuldades é a "burocracia de forma geral e docentes com formação de universidades clássicas, não adequada à formação que a UTFPR se propõe a fazer, no caso, mais tecnológica". Esses resultados vão de encontro às barreiras apresentadas por diversos autores e sistematizadas no Quadro 2, em especial quanto à burocracia universitária e pesquisa universitária não aplicável às necessidades da empresa.

No que tange às ações que poderiam ser realizadas pelos NITs para minimizar as dificuldades, os respondentes mencionaram tanto ações internas à universidade, tais como estimular os servidores a participarem de programa de empreendedorismo e inovação, elaborar manual de processos e procedimentos, elaborar portfólio de competências, maior conhecimento do responsável pelo NIT quanto a leis, regulamentos e procedimentos que regem a temática, tal qual ações externas, como conhecer os problemas do setor produtivo, conhecer a indústria para apresentá-la aos pesquisadores, promover palestra e encontros com empresários para favorecer a aproximação entre ambos e levar a universidade para o setor empresarial.

Quanto aos entraves burocráticos com os quais a UTFPR e os NITs se deparam para promover a relação entre a universidade e as empresas, foram relatados pelos respondentes obstáculos como: "tempo de resposta nosso [da universidade] é muito demorado; não existe preparação para lidar com a indústria" (Entrevistado A); "burocracia interna da UTFPR é grande, para tudo precisa de um respaldo jurídico. Acredito que deveria haver documentos/contratos padrão ou de adesão para dar mais agilidade" (Entrevistado B); "para fechar as parcerias, desde o simples fato de fazer uma visita na empresa é burocrático" (Entrevistado G); "uma barreira hoje é a procuradoria jurídica da universidade, que é inflexível; os regulamentos internos e a procuradoria jurídica deveriam ser mais flexíveis" (Entrevistado J). Essas dificuldades apresentadas pelos entrevistados corroboram com as encontradas na literatura, como mostrado no Quadro 2, principalmente aquelas relacionadas à estrutura das universidades e dos NITs e ao processo de comunicação interna.

Entre as ações que poderiam ser propostas pelos NITs para minimizar esses entraves burocráticos, a resposta mais recorrente foi a necessidade de que a universidade deveria ter documentos padrão para propiciar maior agilidade, além de oferecer treinamentos para o pessoal que trabalha nos NITs. Neste sentido o Entrevistado B citou "modelos de projetos de pesquisa, desenvolvimento e inovação e minutas de contratos com as principais cláusulas; um manual com esclarecimentos para ajudar na efetivação da parceria com empresa".

No que tange às barreiras e/ou dificuldades relacionadas ao pesquisador que prejudicam a efetivação da relação entre a UTFPR e as empresas, o ponto mais presente nas respostas dos entrevistados foi de que a prioridade do docente muitas vezes está relacionada às atividades de ensino, conforme relatado pelo Entrevistado F: "excesso de aulas e orientação". A insegurança do pesquisador em se relacionar com as empresas também foi outro fator citado. Para o Entrevistado A, "o processo de lecionar e pesquisar é mais seguro; falta orientação para a pesquisa ter foco na relação universidade-empresa". Do mesmo modo, para o Entrevistado I há "necessidade de adequar a atividade acadêmica com o desenvolvimento de soluções demandadas pelas empresas". Os entrevistados relataram ainda a falta de interesse das empresas em investir na relação universidade-empresa, bem como a falta de estrutura da universidade, que pode, por vezes, impedir o desenvolvimento dessa cooperação. Essas respostas dos entrevistados são aderentes aos achados na literatura quanto às barreiras encontradas pelos pesquisadores para efetivar a relação universidade-empresa, 
como por exemplo, sobrecarga de atividades, limite de tempo dos professores e falta de capacidade de compreender as necessidades das empresas (Quadro 2).

Em relação aos principais fatores que desestimulam os pesquisadores a realizar seus trabalhos/pesquisas com as empresas, os entrevistados mencionaram: "Pesquisador quer fazer pesquisa apenas para seus pares, porque isso é valorizado; se tiver produção científica já atende as necessidades porque o pesquisador é cobrado por isso" (Entrevistado A); "alta carga tributária e taxas que encarecem os projetos, burocracia e falta de estrutura adequada" (Entrevistado G); "falta de incentivo financeiro ou barreiras burocráticas acabam inviabilizando uma remuneração adequada para o papel desempenhado pelo docente" (Entrevistado I). Esses resultados estão em conformidade com o encontrado na literatura no que tange ao fato de não existir um sistema de recompensas, ou o mesmo ser falho, para os professores/pesquisadores que se relacionam com as empresas (Quadro 2).

No que diz respeito às ações que poderiam ser propostas pelos NITs para minimizar esses fatores, várias sugestões foram apontadas pelos entrevistados, tais como: "edital de inovação com critérios de diferencial inovativo do projeto; indicação no projeto de seu vínculo com o mercado; realizar busca de anterioridade de patentes para os projetos" (Entrevistado A); "incentivar o investimento em pesquisa por meio da divulgação da Lei do Bem e de seus benefícios fiscais" (Entrevistado E); "apontar os benefícios para a universidade e pesquisadores; apresentar cases de sucesso" (Entrevistado G); e "sensibilizar os pesquisadores" (Entrevistado J). Esses resultados coadunam com o apontado por Link, Siegel e Bozeman (2006), Carvalho e Cunha (2013) e Pires (2014), que para fortalecer a relação universidade-empresa uma das ações é a possibilidade de que os recursos em projetos contemplem a parceria universidade-empresa.

Em relação às barreiras e/ou dificuldades relacionadas às empresas que podem dificultar a efetivação da relação universidade-empresa no âmbito da UTFPR, seis entrevistados apontaram como principal obstáculo a diferença de tempo de respostas, ou seja, o timming entre universidade e empresa. Conforme dito pelo entrevistado $B$, "a demora de uma resposta efetiva por parte da universidade; até para dar um retorno para a empresa se tem pessoal capacitado e interessado para atender a demanda é demorado". Foi mencionado ainda como barreira o fato de a empresa considerar o investimento na relação com a universidade como custo e não investimento, conforme dito pelo entrevistado C: "Empresas enxergam a compra do ativo intelectual como custo e não como investimento. A inovação sempre é cercada pela incerteza", e pelo entrevistado J: "Empresários acham que podem se apropriar da universidade por a mesma ser pública. O empresário tradicional não enxerga o papel da universidade como potencial gerador de conhecimento, pesquisa e inovação". Essas barreiras apontadas pelos entrevistados são aderentes às encontradas na literatura (Quadro 2), tais como burocracia universitária, duração longa dos projetos, diferença de nível de conhecimento entre as pessoas da universidade e da empresa e necessidade de mudança de cultura da universidade e do setor produtivo.

Entre as ações que poderiam ser propostas pelos NITs para minimizar essas dificuldades os entrevistados mencionaram a realização de eventos para empresários e a apresentação de cases de sucesso da relação universidade-empresa. Também foi sugerido o diálogo permanente com o setor produtivo e conscientização das vantagens dessa cooperação para ambas as partes. Uma sugestão interessante apresentada pelo Entrevistado I é a criação de um banco de competências da universidade. Em suas palavras, "a criação de um banco de competências utilizando o jargão do setor produtivo, onde estivessem expostas as especialidades dos professores integrantes da unidade e um portfólio de trabalhos já realizados".

Por fim, quanto às ações que entendem como necessárias para que a interação universidade-empresa realmente se efetive na UTFPR, os entrevistados citaram: educação das pessoas no assunto de propriedade intelectual, demonstração das vantagens da relação universidade-empresa para os envolvidos e dicas de como aproximar os atores e fluxos de trabalho para a identificação clara das atribuições de cada ator (universidade, NIT, pesquisador e empresa). Nesse sentido, o Entrevistado I afirmou que:

fundamentalmente um workflow, que identificasse de maneira clara a atribuição de cada um no estabelecimento de parcerias e termos de cooperação, com as devidas responsabilidades e tempos de resposta, que ficasse claro para todos os agentes envolvidos, a começar pela empresa até o último movimento. 
Quando questionados sobre alguma questão relevante e não mencionada na entrevista, o Entrevistado $C$ declarou que "devem haver informações amigáveis", ou seja, de fácil interpretação, "sobre propriedade intelectual em geral e que valorize o pesquisador"; já o Entrevistado G sugeriu a "elaboração de um documento que contenha um mapa geral ou fluxograma de leis e regulamentos" relacionados à matéria.

\section{CONCLUSÃO}

Nesta pesquisa buscou-se compreender como ocorre o processo de interação universidade-empresa na UTFPR intermediado pelos seus NITs. A literatura confirma a importância desse tema na atualidade e o relevante papel dos NITs nesse processo.

A relação universidade-empresa pode representar um motor para $\circ$ desenvolvimento socioeconômico do país. As universidades possuem a capacidade de produzir conhecimento de relevante valor científico e as empresas, por sua vez, podem trazer para a prática o conhecimento presente na academia. Assim, as universidades devem buscar essa aproximação com o condão de estimular o desenvolvimento econômico.

Com advento do Marco Legal de CT\&l este papel ficou mais nítido. Diversos autores corroboram com este fato ao destacarem os NITs como o principal órgão dentro da universidade para fomentar e gerir a política de inovação institucional, bem como para operacionalizar ações que aproximem essas instituições das empresas por meio de seus pesquisadores e projetos por eles desenvolvidos, pela proteção de ativos intelectuais e transferência para o setor produtivo.

A UTFPR tem um histórico de relação com o setor produtivo e sua estrutura organizacional e normativa tem contribuído nessa direção. Os NITs dos diversos campi da universidade atuam como suporte aos pesquisadores e organizam atividades para promover a parceria com empresas, tais como a realização de eventos para empresários, estágios, visitas técnicas em empresas e participação em programas de desenvolvimento regional, dentre outras.

Contudo, diversas barreiras e dificuldades impactam nesse processo, como alta rotatividade dos gestores de inovação e pouca experiência em transferência de tecnologia, burocracia interna, atividades de ensino como prioridade docente e insegurança deste em se relacionar com as empresas, pesquisa universitária não aplicável às necessidades da empresa e o tempo desta ser diferente da universidade, além de falta de interesse das empresas em investir na relação universidade-empresa.

Desse modo, sugere-se que a UTFPR incentive e valorize os pesquisadores para participar de ações que favoreçam a relação universidade-empresa e consolide os mecanismos do Marco Legal de CT\&l em sua política de inovação.

\section{REFERÊNCIAS}

ALGIERI, B.; AQUINO, A.; SUCURRO, M. Technology transfer offices and academic spin-off creation: the case of Italy. Journal of Technology Transfer, v. 38, n. 4, p. 382-400, 2013.

ALVES, V. C.; SEGUNDO, G. S. A.; SAMPAIO, R. R. Reflexões sobre as competências dos Núcleos de Inovação Tecnológica. Cad. Prospec., Salvador, v. 8, n. 4, p. 648-655, 2015.

BARDIN, L. Análise de conteúdo. São Paulo: Edições 70, 2011.

BERNI, J. C. A.; GOMES, C. M.; PERLIN, A. P.; KNEIPP, J. M.; FRIZZO, K. Interação Universidade-Empresa para a Inovação e a Transferência de Tecnologia. GUAL, Florianópolis, v. 8, n. 2, p. 258-277, 2015.

BONNACORSI, A.; PICCALUGA, A. Theoretical framework for the evolution of university-industry relationships. R\&D Management, Oxford, v. 24, n. 3, p. 229-247,1994. 
BRASIL. Lei no 10.973, de 02 de dezembro de 2004. Dispõe sobre incentivos à inovação e à pesquisa científica e tecnológica no ambiente produtivo e dá outras providências. Diário Oficial da União, Brasília, DF. Disponível em: http://www.planalto.gov.br/ccivil_03/_ato2004-2006/2004/lei/l10.973.htm. Acesso em: 16 fev. 2019.

BRASIL. Lei no 13.243, de 11 de janeiro de 2016. Dispõe sobre estímulos ao desenvolvimento científico, à pesquisa, à capacitação científica e tecnológica e à inovação e altera a Lei no 10.973, de 2 de dezembro de 2004, a Lei n 6.815, de 19 de agosto de 1980, a Lei n 8.666, de 21 de junho de 1993, a Lei no 12.462, de 4 de agosto de 2011, a Lei no 8.745, de 9 de dezembro de 1993, a Lei n 8.958, de 20 de dezembro de 1994, a Lei $n^{\circ}$ 8.010, de 29 de março de 1990, a Lei no 8.032, de 12 de abril de 1990, e a Lei no 12.772, de 28 de dezembro de 2012, nos termos da Emenda Constitucional n 85, de 26 de fevereiro de 2015. Diário Oficial da União, Brasília, DF.Disponível em: http://www.planalto.gov.br/ccivil_03/_ato2015-2018/2016/lei/l13243.htm. Acesso em: 05 maio 2019.

CABRERA, R. dos S. Um estudo sobre Núcleos de Inovação e Tecnologia do Sul do Brasil e seu relacionamento com atores do Sistema de Inovação: Proposta de um Quadro Referencial para análise da Inovação e da Transferência de Tecnologia. Dissertação (Mestrado em Engenharia de Produção e Sistemas). Universidade Vale do Rio dos Sinos, São Leopoldo, 2012.

CARVALHO, I. V.; CUNHA, N. C. V.; Proposta de um modelo de transferência de tecnologia para as universidades públicas brasileiras. In: CONGRESSO LATINO-IBEROAMERICANO DE GESTÃO DE TECNOLOGIA ALTEC, 15., 2013, Porto. Anais [...]. Porto: FCT, 2013.

CADORI, A. A. A gestão do conhecimento aplicada ao processo de transferência de resultados de pesquisa de instituições federais de ciência e tecnologia para o setor produtivo: processo mediado pelo núcleo de inovação tecnológica. Tese (Doutorado em Engenharia e Gestão do Conhecimento). Universidade Federal de Santa Catarina. Florianópolis. 2013.

CASTRO, P. G.; TEIXEIRA, A. L. S.; LIMA J. E. A relação entre canais de transferência de conhecimento das Universidades/IPPS e o desempenho inovativo das firmas no Brasil. Revista Brasileira de Inovação, Campinas, v. 13, n. 2, p. 345-370, 2014.

CAPES. COORDENAÇÃO DE APERFEIÇOAMENTO DE PESSOAL DE NÍVEL SUPERIOR. Resolução n 03, de 10 de Dezembro de 2013. Brasília: CAPES, 2013. Disponível em:

https://www.capes.gov.br/images/stories/download/legislacao/Resolucao-3-10dez13-conteudoperiodicos.pdf. Acesso em: 06 maio 2019.

COSTA, C. O. M. Transferência de tecnologia universidade-indústria no Brasil e a atuação de núcleos de inovação tecnológica. Dissertação (Mestrado em Engenharia). Escola Politécnica da Universidade de São Paulo, São Paulo, 2013.

D'ESTE, P.; PERKMANN, M. Why do academic sengage with industry? The entrepreneurial university and individual motivations. Journal of Technology Transfer, v. 36, p. 316-339, 2011.

DESIDÉRIO, P. H. M.; ZILBER, M. A. Barreiras no Processo de Transferência Tecnológica entre Agências de Inovação e Empresas: observações em universidades públicas e privadas. Revista Gestão \& Tecnologia, v. 14, n. 2, p. 99-124, 2014.

DIAS, A.; PORTO, G. S. Gestão de Transferência de Tecnologia na Inova Unicamp. RAC, Rio de Janeiro, v. 17, n. 3, art. 1, p. 263-284, 2013.

DIAS, A.; PORTO, G. S. Como a USP Transfere Tecnologia? Organizações \& Sociedade, v. 21, n. 70, p. 489-508, 2014.

ETZKOWITZ, H. LEYDESDORFF, L. The dynamics of innovation: from national systems and "mode2" to a triple helix of university-industry-government relations. Research Policy, v. 29, p. 109-123, 2000. 
ETZKOWITZ, H.; ZHOU, C. Hélice Tríplice: Inovação e empreendedorismo universidade-indústria-governo. Estudos Avançados, São Paulo, v. 31, n. 90, p. 23-48, 2017.

FABIANO, N. L., de. A comunicação como ferramenta de gestão tecnológica da universidade pública: as agências de inovação. Dissertação (Mestrado em Ciência, Tecnologia e Sociedade). Universidade Federal de São Carlos, São Carlos, 2012.

FERREIRA, A.; AMARAL, M.; LEOPOLDI, M. A. Análise da interação universidade empresa sob a perspectiva do corpo docente: um estudo de caso em uma universidade pública. RACE, v. 12, n. 2, p.677-708, 2013.

FERREIRA. G. C.; SORIA, A. F.; CLOSS, L. Gestão da interação Universidade-Empresa: o caso PUCRS. Sociedade e Estado, v. 27, n. 1, p. 79-94, 2012.

FREITAS JUNIOR, O. G; TONHOLO, J.; CARVALHO, V. D. H.; ÁVILA, T. J. T. Uma arquitetura da informação para portais da inovação das universidades públicas brasileiras. Perspectivas em Gestão \& Conhecimento, v. 3, n. 2, p. 54-74, 2013.

GARNICA, L. A.; TORKOMIAN, A. L. V. Gestão de tecnologia em universidades: uma análise do patenteamento e dos fatores de dificuldade e de apoio à transferência de tecnologia no Estado de São Paulo. Gestão \& Produção, v. 16, n. 4, p. 624-638, 2009.

GIL, A. C. Como elaborar projetos de pesquisa. 6. ed. São Paulo: Atlas, 2008.

KAYMAZ, K.; YASIN-ERYIGIT, K. Determining Factors Hindering University-Industry Collaboration: An Analysis from the Perspective of Academicians in the Context of Entrepreneurial Science Paradigm. International Journal of Social Inquiry, v. 4, n.1, p. 185-213, 2011.

LEMOS, D. C.; CARIO, S. A. F. Análise da interação universidade-empresa para o desenvolvimento inovativo a partir da perspectiva teórica institucionalista-evolucionária. Revista Bras. Inov., Campinas, v. 14, n. 2, p. 361 $382,2015$.

LINK, A.; SIEGEL, D.; BOZEMAN, B. N. Emperical analysis of the propensity of academic stoengage in informal university technology transfer. Renssealer Working Papers of Economics, n. 610, p. 1-24, 2006.

LOTUFO, R. A. A institucionalização de Núcleos de Inovação Tecnológica e a experiência da Inova Unicamp. In: SANTOS, M. E. R. dos; TOLEDO, P.T.M. de; LOTUFO, R. de A. (org.). Transferência de Tecnologia:

estratégias para estruturação e festão de Núcleos de Inovação tecnológica. Campinas - SP: Komedi, 2009. p. 41-74.

MARUYAMA, U.; RAPCHAN, F. A contribuição da rede federal de educação profissional,científica e tecnológica para a inovação: uma análise do FORMICT 2015. In: CONGRESSO NACIONAL DE EXCELÊNCIA EM GESTÃO, 12. 2016, Rio de Janeiro. Anais [...]. Rio de Janeiro: Universidade Federal Flumimense, 2016.

NOVELI, M.; SEGATTO, A. P. Processo de Cooperação Universidade-Empresa para a inovação tecnológica em um parque tecnológico: evidências empíricas e proposição de um modelo conceitual. Revista de

Administração e Inovação, v. 9, n. 1, p. 81-105, 2012.

ORGANIZAÇÃO PARA A COOPERAÇÃO E DESENVOLVIMENTO ECONÔMICO. Manual de Oslo: diretrizes para a coleta e interpretação de dados sobre inovação tecnológica. 4. ed. São Paulo: FINEP, 2018.

PIRES, E. A.; QUINTELLA, C. M. A. T. Política de propriedade intelectual e transferência de tecnologia nas universidades: uma perspectiva do NIT da Universidade Federal do Recôncavo da Bahia. Holos, Natal, v. 6, p. 178-195, 2015.

PIRES, E. A. Mapeamento das estratégias para intensificar a proteção da propriedade intelectual e a transferência de tecnologia: Um estudo de caso da Universidade Federal do Recôncavo Baiano. Dissertação (Mestrado em Ciência da Propriedade Intelectual). Universidade Federal do Sergipe, São Cristóvão, 2014. 
PUFFAL, D. P.; COSTA, A. B. Inovação e a interação universidade-empresa: Uma análise de estudos e a situação brasileira. Competência, Porto Alegre, v. 3, p. 63-82, 2010.

ROSA, R. A. A contribuição da Agência de Inovação da UFPR no processo de transferência tecnológica entre universidade e empresas. Dissertação (Mestrado em Administração). Universidade Federal do Paraná, Curitiba, 2015.

SANTANA, E. E.; PORTO, G. C. E Agora, o que fazer com essa Tecnologia? Um Estudo Multicaso sobre as Possibilidades de Transferência Tecnológica na USP-RP. Revista de Administração Contemporânea, v.13, n. 4, p. 410-429, 2009.

SARTORI, V. InHab-Read - IHR: Metodologia de leitura de entorno para Habitats de Inovação. Tese (Doutorado em Engenharia e Gestão do Conhecimento). Universidade Federal de Santa Catarina, Florianópolis, 2017.

SCHUMPETER, Joseph Alois. Capitalismo, socialismo e democracia. Rio de Janeiro: Zahar, 1984.

SEDLACEK, S. The Role of universities in fostering sustainable development at the regional level. Journal of Cleaner Production, v. 48, p. 74-84, 2013.

SEGATTO-MENDES, A.; SBRAGIA, R. O processo de cooperação universidade empresa em universidades brasileiras. Revista de Administração da Universidade de São Paulo, v. 37, n. 4, p. 58-71, 2002.

SILVA, L. C. S. Processo de Transferência de Tecnologia entre Universidade-Indústria por Intermédio dos Núcleos de Inovação Tecnológica. 102p. Dissertação (Mestrado em Engenharia de Produção). Universidade Tecnológica Federal do Paraná, Ponta Grossa, 2013.

SILVA, L. C. S.; KOVALESKI, J. L.; GAIA, S. Gestão do Conhecimento Organizacional visando à Transferência de Tecnologia: os desafios enfrentados pelo NIT da Universidade Estadual de Santa Cruz. Produção Online, v. 13, n. 2, p. 677-702, 2013.

SILVA, L. R, da. Estudo sobre os padrões de organização e práticas de gestão em núcleo de inovação tecnológica em universidades: análise multicaso entre instituições públicas e privadas. Dissertação (Mestrado em Administração). Centro Universitário da FEl, São Paulo, 2015.

STEFANO, N. M.; SARTORI, S.; LAUX, R. O. Elementos da inovação e empreendedorismo na gestão universitária: portfólio bibliográfico e análise bibliométrica da literatura. Espacios, v. 38, n. 14, p. 33-48, 2017.

SU, D.; ZHOU, D.; LIU, C.; KONG, L. Government-driven university-industry linkages in a emerging country: the case of China. Journal of Science \& Technology Policy Management, v. 6, n. 3, p. 236-282, 2015.

TIDD, J.; BESSANT, J.; PAVITT, K. Gestão da inovação. Bookman. Porto Alegre, 2008.

TOLEDO, P. T. M de. A gestão da inovação em universidades: Evolução, modelos e propostas para instituições brasileiras. Tese (Doutorado em Política Científica e Tecnológica). Instituto Geociências, Universidade Estadual de Campinas, Campinas, 2015.

UNIVERSIDADE TECNOLÓGICA FEDERAL DO PARANÁ. Sobre a UTFPR. 2017. Disponível em: http://portal.utfpr.edu.br/institucional/sobre-a-utfpr-1. Acesso em: 05 maio 2019. 